NBER WORKING PAPER SERIES

\title{
THE CONTRIBUTION OF SCHOOLING IN DEVELOPMENT ACCOUNTING: RESULTS FROM A NONPARAMETRIC UPPER BOUND
}

\author{
Francesco Caselli \\ Antonio Ciccone \\ Working Paper 17656 \\ http://www.nber.org/papers/w17656
NATIONAL BUREAU OF ECONOMIC RESEARCH
1050 Massachusetts Avenue
Cambridge, MA 02138
December 2011

This paper has previously circulated under the title "A Note on Schooling in Development Accounting." We thank Marcelo Soto, Hyun Son, two anonymous referees, and very especially David Weil for useful comments. We also thank the Asian Development Bank for financial support. The views expressed herein are those of the authors and do not necessarily reflect the views of the National Bureau of Economic Research.

NBER working papers are circulated for discussion and comment purposes. They have not been peerreviewed or been subject to the review by the NBER Board of Directors that accompanies official NBER publications.

(C) 2011 by Francesco Caselli and Antonio Ciccone. All rights reserved. Short sections of text, not to exceed two paragraphs, may be quoted without explicit permission provided that full credit, including (C) notice, is given to the source. 
The Contribution of Schooling in Development Accounting: Results from a Nonparametric

Upper Bound

Francesco Caselli and Antonio Ciccone

NBER Working Paper No. 17656

December 2011, Revised October 2012

JEL No. E0,E00,E01,O0,O1,O10,O11,O15,O3,O30

\begin{abstract}
How much would output increase if underdeveloped economies were to increase their levels of schooling? We contribute to the development accounting literature by describing a non-parametric upper bound on the increase in output that can be generated by more schooling. The advantage of our approach is that the upper bound is valid for any number of schooling levels with arbitrary patterns of substitution/ complementarity. Another advantage is that the upper bound is robust to certain forms of endogenous technology response to changes in schooling. We also quantify the upper bound for all economies with the necessary data, compare our results with the standard development accounting approach, and provide an update on the results using the standard approach for a large sample of countries.
\end{abstract}

Francesco Caselli

Department of Economics

London School of Economics

Houghton Street

London WC2A 2AE

UNITED KINGDOM

and CEPR

and also NBER

f.caselli@1se.ac.uk

Antonio Ciccone

Universitat Pompeu Fabra

and CEPR

antonio.ciccone@upf.edu 


\section{Introduction}

Low GDP per worker goes together with low schooling. For example, in the country with the lowest output per worker in 2005, half the adult population has no schooling at all and only $5 \%$ has a college degree (Barro and Lee, 2010). In the country with output per worker at the 10th percentile, $32 \%$ of the population has no schooling and less than $1 \%$ a college degree. In the country at the 25 th percentile, the population shares without schooling and with a college degree are $22 \%$ and $1 \%$ respectively. On the other hand, in the US, the share of the population without schooling is less than $0.5 \%$ and $16 \%$ have a college degree.

To some extent, such differences in attainment could reflect efficient schooling decisions in response to international differences in technology or institutional quality (e.g. Foster and Rosenzweig, 1995; Rosenzweig and Munshi, 2006; Jensen, 2010). On the other hand, it seems highly plausible that schooling attainment in poor countries is also limited by lack of access to schools (particularly in rural areas), and credit constraints that force parents to send children to work in order to provide for current consumption. Credit constraints also limit poor parents' capacity to cover tuition, uniforms, and meals. Consistent with the view that there are barriers to investment in schooling, Duflo (2001) finds large enrollment effects from an expansion in public school provision, and Schultz (2004) from the introduction of a conditional cash transfer program. The crucial importance of public funding (and other government policies) to enable mass schooling is discussed at length in Goldin and Katz (2008). It is also consistent with the existence of barriers to attainment that the returns to schooling are higher in poor countries than in rich ones (e.g. Bils and Klenow, 2000). The view that schooling attainment is in part limited by lack of access and credit constraints has led national governments, bilateral and multilateral donors, and civil-society NGOs to prioritize schooling attainment among their development goals for several decades. For example, one of the millennium development goals is universal education.

But how much of the output gap between developing and rich countries can be accounted for by differences in the quantity of schooling? Early empirical attempts to answer this question using cross-country data focused on regressions of growth (or GDP levels) on measures of educational enrollment or attainment (e.g. Barro, 1991; Mankiw, Romer and Weil, 1992; Benhabib and Spiegel, 1994; Caselli, Esquivel, and Lefort, 1996; see Krueger and Lindhal, 2001 for a survey and evaluation of this literature). One difficulty with this literature is that results on the impact of schooling did not prove robust to alternative measures of the education variable, the sample, or the estimation method. Also, 
it proved difficult to tackle the problem of endogeneity of schooling.

In part in response to these difficulties with the regression approach, a second wave of studies focused on calibration rather than estimation (e.g. Klenow and Rodriguez-Clare, 1997; Hall and Jones, 1999; Hendricks, 2002), giving rise to a thriving new literature known as development accounting. A robust result in the development accounting literature is that only a relatively small fraction of the output gap between developing and rich countries can be attributed to differences in the quantity of schooling. ${ }^{1}$ This result appears to dampen expectations that current efforts at boosting schooling in poor countries, even if successful, will do much to close the gaps in living standards. ${ }^{2}$

The somewhat negative result from development accounting is obtained using a parametric approach. Technology differences across countries are assumed to be skill neutral, and workers with different attainment are perfect substitutes. Relative wages are then used to gauge the relative efficiency in production of workers with different attainment. A potential concern is that there is by now a consensus that differences in technology across countries or over time are generally not Hicks-neutral, and that perfect substitutability among different schooling levels is rejected by the empirical evidence (e.g. Katz and Murphy, 1992; Angrist, 1995; Goldin and Katz, 1998; Autor and Katz, 1999; Krusell et al., 2000; Ciccone and Peri, 2005; and Caselli and Coleman, 2006). Once the assumptions of perfect substitutability among schooling levels and Hicksneutral technology differences are discarded, can we still say something about the output gap between developing and rich countries attributable to schooling?

Answering this question while sticking to a parametric approach re-

\footnotetext{
${ }^{1}$ Recently this result has been challenged by Gennaioli et al. (2012), who argue that much of top managers' and entrepreneurs' returns to schooling are formally earned as profits, and therefore unaccounted for by standard microeconomic estimates of the returns to schooling - a key ingredient in most development-accounting calculations. After accounting for managers' returns to schooling, they argue that the average Mincerian return to schooling is around 20\%, about double what is usually found in the literature. Using this higher return leads to a large increase in the explanatory power of human capital for income differences. Gennaioli et al.'s estimate of managers' returns to schooling is based on firm-level valued-added regressions that do not control for manager characteristics other than schooling. As such characteristics may be correlated with managers' schooling, it is difficult to know what part of the return can be attributed to schooling only.

${ }^{2}$ Partially in response to these findings, some authors have advocated a shift to cross-country differences in the quality of schooling (e.g. Hanushek and Woessmann, 2008, 2011; Erosa et al., 2010; Manuelli and Seshadri, 2010). Other authors have emphasized aspects of human capital such as health (Weil, 2007) and experience (Lagakos et al., 2012).
} 
quires assuming that there are only two imperfectly substitutable skill types, that the elasticity of substitution between these skill types is the same in all countries, and that this elasticity of substitution is equal to the elasticity of substitution in countries where instrumental-variable estimates are available (e.g. Angrist, 1995; Ciccone and Peri, 2005). These assumptions are quite strong. For example, the evidence indicates that dividing the labor force in just two skill groups misses out on important margins of substitution (Autor et al., 2006; Goos and Manning, 2007). Once there are more than 3 skill types, estimation of elasticities of substitution becomes notoriously difficult for two main reasons. First, there are multiple, non-nested ways of capturing patterns of substitutability/complementarity and this make it difficult to avoid misspecification (e.g. Duffy et al., 2004). Second, relative skill supplies and relative wages are jointly determined in equilibrium and estimation therefore requires instruments for relative supplies. It is already challenging to find convincing instruments for two skill types and we are not aware of instrumental-variables estimates when there are 3 or more imperfectly substitutable skills groups.

We explore an alternative to the parametric production function approach. In particular, we make the observation that when aggregate production functions are weakly concave in inputs, assuming perfect substitutability among different schooling levels yields an upper bound on the increase in output that can be generated by more schooling. This is true irrespective of the pattern of substitutability/complementarity among schooling levels, as well as the pattern of cross-country non-neutrality in technology. This basic observation does not appear to have been made in the development accounting literature. It is worthwhile noting that the production functions used in the development accounting literature satisfy the assumption of weak concavity in inputs. Hence, our approach yields an upper bound on the increase one would obtain using the production functions in the literature. Moreover, the assumption of weakly concave aggregate production functions is fundamental for the development accounting approach as it is clear that without it, inferring marginal productivities from market prices cannot yield interesting insights into the factors accounting for differences in economic development.

The intuition for why the assumption of perfect substitutability yields an upper bound on the increase in output generated by more schooling is easiest to explain in a model with two schooling levels, schooled and unschooled. In this case, an increase in the share of schooled workers has, in general, two types of effects on output. The first effect is that more schooling increases the share of more productive workers, which increases output. The second effect is that more schooling raises the marginal 
productivity of unschooled workers and lowers the marginal productivity of schooled workers. When assuming perfect substitutability between schooling levels, one rules out the second effect. This implies an overstatement of the output increase when the production function is weakly concave, because the increase in the marginal productivity of unschooled workers is more than offset by the decrease in the marginal productivity of schooled workers. The result that increases in marginal productivities produced by more schooling are more than offset by decreases in marginal productivities continues to hold for an arbitrary number of schooling types with any pattern of substitutability/complementarity as long as the production function is weakly concave. Hence, assuming perfect substitutability among different schooling levels yields an upper bound on the increase in output generated by more schooling.

From the basic observation that assuming perfect substitutability among schooling levels yields an upper bound on output increases, and with a few ancillary assumptions - mainly that physical capital adjusts to the change in schooling so as to keep the marginal product of physical capital unchanged - we derive a formula that computes the upper bound using exclusively data on the structure of relative wages of workers with different schooling levels. We apply our upper-bound calculations to two data sets. In one data set of 9 countries we have detailed wage data for up to 10 schooling-attainment groups for various years between 1960 and 2005. In another data set of about 90 countries we use evidence on Mincerian returns to proxy for the structure of relative wages among 7 attainment groups. Our calculations yield output gains from reaching a distribution of schooling attainment similar to the US that are sizeable as a proportion of initial output. However, these gains are much smaller when measured as a proportion of the existing output gap with the US. These results are in line with the conclusions from development accounting (e.g. Klenow and Rodriguez-Clare, 1997; Hall and Jones, 1999; Caselli, 2005). This is not surprising as these studies assume that workers with different schooling attainment are perfect substitutes and therefore end up working with a formula that is very similar to our upper bound.

A potential limitation of the parametric approach to development accounting is that it typically assumes that changes in schooling attainment leave technology unchanged. ${ }^{3}$ This assumption would be wrong if

\footnotetext{
${ }^{3}$ This is not always the case however. For example, a recent paper by Jones (2011) computes rich-poor human capital ratios using relative wages in poor as well as rich countries. His approach implies that computed human capital ratios will also reflect differences in human capital quality and - to the extent they affect relative wages differences in technology. In Jones' framework, the perfect substitution case yields a
} 
there were important schooling externalities or significant appropriatetechnology effects. We discuss the extent to which our nonparametric upper bound is robust to endogenous technology responses. Perhaps surprisingly, we find that our approach also works in the appropriatetechnology framework developed and estimated by Caselli and Coleman (2006). On the other hand, and less surprisingly, our approach does not yield an upper bound in the presence of aggregate schooling externalities. However, the empirical evidence suggests that such externalities are not large enough for our upper bound to be far off. We therefore conclude that our upper-bound calculations could well continue to be useful even in a world where technology responds endogenously to relative skill supplies.

The rest of the paper is organized as follows. Section 2 derives the upper bound. Section 3 shows the results from our calculations. Section 4 discusses the robustness of our upper-bound calculation to making technology endogenous to schooling. Section 5 concludes.

\section{Derivation of the Upper Bound}

Suppose that output $Y$ is produced with physical capital $K$ and workers with different levels of schooling attainment,

$$
Y=F\left(K, L_{0}, L_{1}, \ldots L_{m}\right)
$$

where $L_{i}$ denotes workers with schooling attainment $i=0, . ., m$. The (country-specific) production function $F$ is assumed to be increasing in all arguments, subject to constant returns to scale, and weakly concave in inputs. Moreover, $F$ is taken to be twice continuously differentiable.

The question we want to answer is: how much would output per worker in a country increase if workers were to have more schooling. Specifically, define $s_{i}$ as the share of the labor force with schooling attainment $i$, and $\mathbf{s}=\left[s_{0}, s_{1} . ., s_{i, \ldots} s_{m}\right]$ as the vector collecting all the shares. We want to know the increase in output per worker if schooling were to change from the current schooling distribution $\mathbf{s}^{1}$ to a schooling distribution $\mathbf{s}^{2}$ with more weight on higher schooling attainment. For example, $\mathbf{s}^{1}$ could be the current distribution of schooling attainment in India and $\mathbf{s}^{2}$ the distribution in the US. Our problem is that we do not know the production function $F$.

To start deriving an upper bound for the increase in output per worker that can be generated by additional schooling, denote physical capital per worker by $k$ and note that constant returns to scale and weak

lower bound on the income increase that can be achieved by raising human capital in poor countries. 
concavity of the production function in (1) imply that changing inputs from $\left(k^{1}, \mathbf{s}^{1}\right)$ to $\left(k^{2}, \mathbf{s}^{2}\right)$ generates a change in output per worker $y^{2}-y^{1}$ that satisfies

$$
y^{2}-y^{1} \leq F_{k}\left(k^{1}, \mathbf{s}^{1}\right)\left(k^{2}-k^{1}\right)+\sum_{i=0}^{m} F_{i}\left(k^{1}, \mathbf{s}^{1}\right)\left(s_{i}^{2}-s_{i}^{1}\right)
$$

where $F_{k}\left(k^{1}, \mathbf{s}^{1}\right)$ is the marginal product of physical capital given inputs $\left(k^{1}, \mathbf{s}^{1}\right)$ and $F_{i}\left(k^{1}, \mathbf{s}^{1}\right)$ is the marginal product of labor with schooling attainment $i$ given inputs $\left(k^{1}, \mathbf{s}^{1}\right)$. Hence, the linear expansion of the production function is an upper bound for the increase in output per worker generated by changing inputs from $\left(k^{1}, \mathbf{s}^{1}\right)$ to $\left(k^{2}, \mathbf{s}^{2}\right)$.

We will be interested in percentage changes in output per worker and therefore divide both sides of (2) by $y^{1}$,

$$
\frac{y^{2}-y^{1}}{y^{1}} \leq \frac{F_{k}\left(k^{1}, \mathbf{s}^{1}\right) k^{1}}{y^{1}}\left(\frac{k^{2}-k^{1}}{k^{1}}\right)+\sum_{i=0}^{m} \frac{F_{i}\left(k^{1}, \mathbf{s}^{1}\right)}{y^{1}}\left(s_{i}^{2}-s_{i}^{1}\right) .
$$

Assume now that factor markets are approximately competitive. Then (3) can be rewritten as

$$
\frac{y^{2}-y^{1}}{y^{1}} \leq \alpha^{1}\left(\frac{k^{2}-k^{1}}{k^{1}}\right)+\left(1-\alpha^{1}\right)\left(\sum_{i=0}^{m}\left(\frac{w_{i}^{1}}{\sum_{i=0}^{m} w_{i}^{1} s_{i}^{1}}\right)\left(s_{i}^{2}-s_{i}^{1}\right)\right)
$$

where $\alpha^{1}$ is the physical capital share in output and $w_{i}^{1}$ is the wage of workers with schooling attainment $i$ given inputs $\left(k^{1}, \mathbf{s}^{1}\right)$. Since schooling shares must sum up to unity we have $\sum_{i=0}^{m} w_{i}^{1}\left(s_{i}^{2}-s_{i}^{1}\right)=\sum_{i=1}^{m}\left(w_{i}^{1}-w_{0}^{1}\right)\left(s_{i}^{2}-\right.$ $\left.s_{i}^{1}\right)$ and $w^{1}=w_{0}^{1}+\sum_{i=1}^{m}\left(w_{i}^{1}-w_{0}^{1}\right) s_{i}^{1}$ and, (4) becomes

$$
\frac{y^{2}-y^{1}}{y^{1}} \leq \alpha^{1}\left(\frac{k^{2}-k^{1}}{k^{1}}\right)+\left(1-\alpha^{1}\right)\left(\frac{\sum_{i=1}^{m}\left(\frac{w_{i}^{1}}{w_{0}^{1}}-1\right)\left(s_{i}^{2}-s_{i}^{1}\right)}{1+\sum_{i=1}^{m}\left(\frac{w_{i}^{1}}{w_{0}^{1}}-1\right) s_{i}^{1}}\right) .
$$

Hence, the increase in output per worker that can be generated by additional schooling and physical capital is below a bound that depends on the physical capital income share and the wage premia of different schooling groups relative to a schooling baseline.

\subsection{Optimal Adjustment of Physical Capital}

In (5), we consider an arbitrary change in the physical capital intensity. As a result, the upper bound on the increase in output that can be generated by additional schooling may be off because the change in physical 
capital considered is suboptimal given schooling attainment. We now derive an upper bound that allows physical capital to adjust optimally (in a sense to be made clear shortly) to the increase in schooling. To do so, we have to distinguish two scenarios. A first scenario where the production function is weakly separable in physical capital and schooling, and a second scenario where schooling and physical capital are not weakly separable. In this section we develop the first of these cases, while in the appendix we develop the latter.

Assume that the production function for output can be written as

$$
Y=F\left(K, G\left(L_{0}, L_{1}, \ldots L_{m}\right)\right)
$$

with $F$ and $G$ characterized by constant returns to scale and weak concavity. This formulation implies that the marginal rate of substitution in production between workers with different schooling is independent of the physical capital intensity. While this separability assumption is not innocuous, it is weaker than the assumption made in most of the development accounting literature. ${ }^{4}$

We also assume that as the schooling distribution changes from the original schooling distribution $\mathbf{s}^{1}$ to a schooling distribution $\mathbf{s}^{2}$, physical capital adjusts to leave the marginal product of capital unchanged, $M P K^{2}=M P K^{1}$. This could be because physical capital is mobile internationally or because of physical capital accumulation in a closed economy. ${ }^{5}$ With these two assumptions we can develop an upper bound for the increase in output per worker that can be generated by additional schooling, that depends on the wage premia of different schooling groups only. To see this, note that separability of the production function implies

$$
\frac{y^{2}-y^{1}}{y^{1}} \leq \alpha^{1}\left(\frac{k^{2}-k^{1}}{k^{1}}\right)+\left(1-\alpha^{1}\right)\left(\frac{G\left(\mathbf{s}^{2}\right)-G\left(\mathbf{s}^{1}\right)}{G\left(\mathbf{s}^{1}\right)}\right) \text {. }
$$

The assumption that physical capital adjusts to leave the marginal product unchanged implies that $F_{1}\left(k^{1} / G\left(\mathbf{s}^{1}\right), 1\right)=F_{1}\left(k^{2} / G\left(\mathbf{s}^{2}\right), 1\right)$ and therefore $k^{2} / G\left(\mathbf{s}^{2}\right)=k^{1} / G\left(\mathbf{s}^{1}\right)$. Substituting in $(7)$,

$$
\frac{y^{2}-y^{1}}{y^{1}} \leq \frac{G\left(\mathbf{s}^{2}\right)-G\left(\mathbf{s}^{1}\right)}{G\left(\mathbf{s}^{1}\right)} .
$$

\footnotetext{
${ }^{4}$ Which assumes that the function $F$ in $(6)$ is Cobb-Douglas, often based on Gollin's (2002) finding that the physical capital income share does not appear to vary systematically with the level of economic development. In the Appendix we show that our approach can be extended to the case where physical capital displays stronger complementaries with higher levels of schooling.

${ }^{5}$ See Caselli and Feyrer (2007) for evidence that the marginal product of capital is not systematically related to the level of economic development.
} 
Weak concavity and constant returns to scale of $G$ imply, respectively, $G\left(\mathbf{s}^{2}\right)-G\left(\mathbf{s}^{1}\right) \leq \sum_{i=0}^{m} G_{i}\left(\mathbf{s}^{1}\right)\left(s_{i}^{2}-s_{i}^{1}\right)$ and $G\left(\mathbf{s}^{1}\right)=\sum_{i=0}^{m} G_{i}\left(\mathbf{s}^{1}\right) s_{i}^{1}$, where $G_{i}$ denotes the derivative with respect to schooling level $i$. Combined with (7), this yields

$$
\frac{y^{2}-y^{1}}{y^{1}} \leq \frac{\sum_{i=0}^{m} G_{i}\left(\mathbf{s}^{1}\right)\left(s_{i}^{2}-s_{i}^{1}\right)}{\sum_{i=0}^{m} G_{i}\left(\mathbf{s}^{1}\right) s_{i}^{1}}=\frac{\sum_{i=1}^{m}\left(\frac{w_{i}^{1}}{w_{0}^{1}}-1\right)\left(s_{i}^{2}-s_{i}^{1}\right)}{1+\sum_{i=1}^{m}\left(\frac{w_{i}^{1}}{w_{0}^{1}}-1\right) s_{i}^{1}}
$$

where the equality makes use of the fact that separability of the production function and competitive factor markets imply

$$
\frac{G_{i}\left(\mathbf{s}^{1}\right)}{G_{0}\left(\mathbf{s}^{1}\right)}=\frac{F_{2}\left(k^{1}, G\left(\mathbf{s}^{1}\right)\right) G_{i}\left(\mathbf{s}^{1}\right)}{F_{2}\left(k^{1}, G\left(\mathbf{s}^{1}\right)\right) G_{0}\left(\mathbf{s}^{1}\right)}=\frac{w_{i}^{1}}{w_{0}^{1}} .
$$

Hence, assuming weak separability between physical capital and schooling, the increase in output per worker that can be generated by additional schooling is below a bound that depends on the wage premia of different schooling groups relative to a schooling baseline.

\subsection{The Upper Bound with a Constant Marginal Return to Schooling}

The upper bound on the increase in output per worker that can be generated by additional schooling in (9) becomes especially simple when the wage structure entails a constant return to each additional year of schooling, $\left(w_{i}-w_{i-1}\right) / w_{i-1}=\gamma$. This assumption is often made in development accounting, because for many countries the only data on the return to schooling available is the return to schooling estimated using Mincerian wage regressions (which implicitly assume $\left(w_{i}-w_{i-1}\right) / w_{i-1}=$ $\gamma$ ). In this case, the upper bound for the case of weak separability between schooling and physical capital in (9) becomes

$$
\frac{y^{2}-y^{1}}{y^{1}} \leq \frac{\sum_{i=1}^{m}\left((1+\gamma)^{x_{i}}-1\right)\left(s_{i}^{2}-s_{i}^{1}\right)}{1+\sum_{i=1}^{m}\left((1+\gamma)^{x_{i}}-1\right) s_{i}} .
$$

where $x_{i}$ is years of schooling corresponding to schooling attainment $i$ (schooling attainment 0 is assumed to entail zero years of schooling).

The upper-bound calculation using (11) is closely related to analogous calculations in the development accounting literature. In development accounting, a country's human capital is typically calculated as

$$
(1+\gamma)^{S}
$$


where $S$ is average years of schooling and the average marginal return to schooling $\gamma$ is using evidence on Mincerian coefficients. ${ }^{6}$ One difference with our approach is therefore that development accounting calculations identify a country's schooling capital with the schooling capital of the average worker, while our upper-bound calculation uses the (more theoretically grounded) average of the schooling capital of all workers. The difference, as already mentioned, is Jensen's inequality. ${ }^{7}$ Another difference is that we use country-specific Mincerian returns while development accounting often uses a common value (or function) for all countries.

\subsection{Link to Development Accounting and Graphi- cal Intuition}

At this point it is worthwhile discussing the relationship between our analysis of schooling's potential contribution to output per worker differences across countries and the analysis in development accounting. Following Klenow and Rodriguez-Clare (1996), development accounting usually assesses the role of schooling for output per worker under the assumption that workers with different schooling are perfect substitutes in production. This assumption has been made because it is necessary to explain the absence of large cross-country differences in the return to schooling when technology is Hick-neutral (e.g. Klenow and Rodriguez-Clare, 1996; Hendricks, 2002). But there is now a consensus that differences in technology across countries or over time are generally not Hicks-neutral and that perfect substitutability among different schooling levels is rejected by the empirical evidence, see Katz and Murphy (1992), Angrist (1995), Goldin and Katz (1998), Autor and Katz (1999), Krusell et al. (2000), Ciccone and Peri (2005), Caselli and Coleman (2006). Moreover, the elasticity of substitution between more and

\footnotetext{
${ }^{6}$ More accurately, human capital is usually calculated as $\exp (\gamma S)$, but the two expressions are approximately equivalent and the one in the text is more in keeping with our previous notation.

${ }^{7}$ To see the relation more explicitly, for small $\gamma,(1+\gamma)^{x_{i}}$ is approximately linear and the right-hand side of (11) can be written in terms of average years of schooling $S=\sum_{i=1}^{m} x_{i} s_{i}$, as we do not miss much by ignoring Jensen's inequality and assuming $\sum_{i=0}^{m}(1+\gamma)^{x_{i}} s_{i} \approx(1+\gamma)^{S}$. As a result, if the Mincerian return to schooling is small, the upper bound on the increase in output per worker that can be generated by more schooling depends on the Mincerian return and average schooling only$$
\frac{y^{2}-y^{1}}{y^{1}} \leq \frac{(1+\gamma)^{S^{2}}-(1+\gamma)^{S^{1}}}{(1+\gamma)^{S^{1}}}
$$

Another approximation of the right-hand side of (11) for small $\gamma$ that is useful for relating our upper bound to the development accounting literature is $\gamma\left(S^{2}-\right.$ $\left.S^{1}\right) /\left(1+\gamma S^{1}\right)$.
} 
less educated workers found in this literature is rather low (between 1.3 and 2, see Ciccone and Peri, 2005 for a summary).

Hence, the assumption of perfect substitutability among different schooling levels often made in development accounting should be discarded. But this does not mean that the findings in the development accounting literature have to be discarded also. To understand why note that the right-hand side of (9) - our upper bound on the increase in output per worker generated by more schooling - is exactly equal to the output increase one would have obtained under the assumption that different schooling levels are perfect substitutes in production, $G\left(L_{0}, L_{1}, \ldots, L_{m}\right)=a_{0} L_{0}+a_{1} L_{1}+\ldots+a_{m} L_{m}$. Hence, although rejected empirically, the assumption of perfect substitutability among different schooling levels remains useful in that it yields an upper bound on the output increase that can be generated by more schooling.

To develop an intuition for these results, consider the case of just two labor types, skilled and unskilled, and no capital,

$$
Y=G\left(L_{U}, L_{H}\right)
$$

where $G$ is taken to be subject to constant returns to scale and weakly concave. Suppose we observe the economy when the share of skilled labor in total employment is $s^{1}$ and want to assess the increase in output per worker generated by increasing the skilled-worker share to $s^{2}$. The implied increase in output per worker can be written as

$$
\begin{aligned}
y\left(s^{2}\right)-y\left(s^{1}\right) & =G\left(1-s^{2}, s^{2}\right)-G\left(1-s^{1}, s^{1}\right) \\
& =\int_{s^{1}}^{s^{2}} \frac{\partial G(1-s, s)}{\partial s} d s \\
& =\int_{s^{1}}^{s^{2}}\left[G_{2}(1-s, s)-G_{2}(1-s, s)\right] d s .
\end{aligned}
$$

Weak concavity of $G$ implies that $G_{2}(1-s, s)-G_{1}(1-s, s)$ is either flat or downward sloping in $s$. Hence, (14) implies that $y\left(s^{2}\right)-y\left(s^{1}\right) \leq$ $\left[G_{2}\left(1-s^{1}, s^{1}\right)-G_{1}\left(1-s^{1}, s^{1}\right)\right]\left(s^{2}-s^{1}\right)$. Moreover, when factor markets are perfectly competitive, the difference between the observed skilled and unskilled wage in the economy $w_{H}^{1}-w_{U}^{1}$ is equal to $G_{2}\left(1-s^{1}, s^{1}\right)-$ $G_{1}\left(1-s^{1}, s^{1}\right)$. As a result, $y\left(s^{2}\right)-y\left(s^{1}\right) \leq\left(w_{H}^{1}-w_{U}^{1}\right)\left(s^{2}-s^{1}\right)$. As $\left(w_{H}^{1}-w_{U}^{1}\right)\left(s^{2}-s^{1}\right)$ is also the output increase one would have obtained under the assumption that the two skill types are perfect substitutes, it follows that our upper bound is equal to the increase in output assuming perfect substitutability between skill types. Figure 1 illustrates this calculation graphically. ${ }^{8}$ The increase in output is the pink area.

\footnotetext{
${ }^{8}$ We thank David Weil for suggesting this figure.
} 
The upper bound is the pink plus blue area. The figure also illustrates that the difference between our upper bound and the true output gain is larger - making our upper bound less tight - the larger the increase in schooling considered. ${ }^{9}$

It is important to note that once perfect substitutability has been discarded, the particular way the development accounting question is asked becomes very important. There are two main ways the question has been asked in the literature. The first is the one in Hall and Jones (1999) which is also the focus of our paper: by how much would the output gap shrink if the capital inputs of a factor scarce country increased to the level of a factor rich country? The second way is to follow Klenow and Rodriguez-Clare (1997) and ask what fraction of the variance in income is attributable to variation in a certain factor. Such decompositions are difficult once skill-biased technology and imperfect substitutability among skills are allowed for. What we have shown is that the perfect substitution case provides an upper bound for the answer to the Hall and Jones question. ${ }^{10}$

\section{Estimating the Upper Bounds}

We now estimate the maximum increase in output that could be generated by increasing schooling to US levels. We first do this for a subsample of countries and years for which we have data allowing us to perform the calculation in equation (9). For these countries we can also compare the results obtained using (9) with those using (11), which assume a constant return to extra schooling. These comparisons put in perspective the reliability of the estimates that are possible for larger samples, where only Mincerian returns are available. We also report such calculations for a large cross-section of countries in 1990.

\subsection{Using Group-Specific Wages}

We implement the upper-bound calculation in equation (9) for 9 countries for which we are able to estimate wages by education attainment level using national censa data from the international IPUMS (Min-

\footnotetext{
${ }^{9}$ Our implementation of the upper bound below considers US schooling levels as the arrival value. As a result, the increase in schooling considered is large for many developing countries and our upper bound could be substantially larger than the true output gain.

${ }^{10}$ In principle there is a third way of phrasing the question of development accounting: by how much would output in a factor-rich country fall if its factor endowment fell to the level of a factor-poor country. Our main result implies that when the production function is weakly concave in inputs, the decrease in output generated by a fall in schooling is always greater than the decrease predicted under the assumption of perfect substitutability.
} 
nesota Population Center, 2011). The countries are Brazil, Colombia, Jamaica, India, Mexico, Panama, Puerto Rico, South Africa, and Venezuela, with data for multiple years between 1960 and 2007 for most countries. The details vary somewhat from country to country as (i) schooling attainment is reported in varying degrees of detail across countries; (ii) the concept of income varies across countries; and (iii) the control variables available also vary across countries. See Appendix Tables 1-3 for a summary of the micro data (e.g. income concepts; number of attainment levels; control variables available; number of observations) and our Supplementary Appendix for country-by-country data and estimation results. These data allow us to estimate attainment-specific returns to schooling and implement (9) using the observed country-year specific distribution of educational attainments and the US distribution of educational attainment in the corresponding year as the arrival value.

It is worthwhile noting that in implementing (9) - and also (11) below - we estimate and apply returns to schooling that vary both across countries and over time. Given our setup, the most immediate interpretation of the variation in returns to schooling would be that there is imperfect substitutability between workers with different schooling attainments and that the supply of different schooling attainments varies over time and across countries. It is exactly the presence of imperfect substitutability among different schooling levels that motivates our upper-bound approach. Another reason why returns to schooling might vary could be that there are differences in technology. Our upperbound approach does not require us to put structure on such (possibly attainment-specific) technology differences. As we discuss in Section 4, our upper-bound calculation may continue to be correct even under particular ways in which technology changes in response to changes in schooling. ${ }^{11}$

The results of implementing the upper-bound calculation in (9) for each country-year are presented (in bold face) in Table 1. For this group of countries applying the upper-bound calculation leads to conclusions that vary significantly both across countries and over time. The largest computed upper-bound gain is for Brazil in 1970, which is of the order of $150 \%$. This result largely reflects the huge gap in schooling between the US and Brazil in that year (average years of schooling in Brazil was less than 4 in 1970). The smallest upper bound is for Puerto Rico in 2005, which reflects the high schooling attainment by that year (average years of schooling is almost 13). The average is 0.59 .

\footnotetext{
${ }^{11}$ Another possible source of differences in schooling returns across countries is sampling variation. However our estimates of both attainment specific and Mincerian returns are extremely precise, so we think this explanation is unlikely.
} 
A different metric is the fraction of the overall output gap with the US that reaching US attainment levels can cover. This calculation is also reported in Table 1 (characters in normal type). As a proportion of the output gap, the largest upper-bound gain is for Brazil in 1980 (57\%), while the smallest is again for Puerto Rico in 2005 (virtually zero). On average, at the upper bound, attaining the US education distribution allows countries to cover $21 \%$ of their output gap with the US.

The shortcoming of the results in Table 1 is that they refer to a quite likely unrepresentative sample. For this reason, we now ask whether using the approach in equation (11) leads to an acceptable approximation of (9). As we show in the next section, data to implement (11) is readily available for a much larger (and arguably representative) sample of countries, so if (11) offers an acceptable approximation to (9) we can be more confident on results from larger samples.

To implement (11), we first use our micro data to estimate Mincerian returns for each country-year. This is done with an OLS regression using the same control variables employed to estimate the attainment-specific returns to schooling above. ${ }^{12}$ See Appendix Table 2 for point estimates and standard errors of Mincerian returns for each country-year. Once we have the Mincerian return we can apply equation (11) to assess the upper-bound output gains of increasing the supply of schooling (assuming that technology remains unchanged). The results are reported, as a fraction of the results using (9), in the first row of Table 2 (bold type). This exercise reveals differences between the calculations in (9) and (11). On average, the calculation that imposes a constant proportional wage gain yields only $77 \%$ of the calculation that uses attainment-specific returns to schooling. Therefore, the first message from this comparison is that, on average, basing the calculation on Mincerian coefficients leads to a significant underestimate of the upper-bound output increase associated with attainment gains. However, there is enormous heterogeneity in the gap between the two estimates, and the results from (11) are not uniformly below those from (9). Almost one third of the estimates based on (11) are larger. The significant average difference in estimates and the great variation in this difference strongly suggest that whenever possible it would be advisable to use detailed data on the wage structure rather than a single Mincerian return coefficient. It is interesting to note that the ratio of (11) to (9) is virtually uncorrelated with per-worker GDP. To put it differently, while estimates based on (11) are clearly imprecise, the error relative to (9) is not systematically related to per-worker output. Hence, one may conclude that - provided the appropriate allowance is

\footnotetext{
${ }^{12}$ The empirical labor literature finds that OLS estimates of Mincerian returns to schooling are often close to causal estimates, see Card (1999).
} 
made for the average gap between (11) and (9) - some broad conclusions using (11) are still possible.

We can also compare the results of our approach in (9) to the calculation combining average years of schooling with a single Mincerian return in (11). The results are reported in the second rows of Table 2. On average, the results are extremely close to those using (11), suggesting that ignoring Jensen's inequality is not a major source of error in the calculations. However, the variation around this average is substantial.

\subsection{Using Mincerian Returns Only}

The kind of detailed data on the distribution of wages that is required to implement the calculation in equation (9) is not often available. However, there are estimates of the Mincerian return to schooling for many countries and years. For such countries, it is possible to implement the approximation in (11).

We begin by choosing 1990 as the reference year. For Mincerian returns we use a collection of published estimates assembled by Caselli (2010). This starts from previous collections, most recently by Bils and Klenow (2003), and adds additional observations from other countries and other periods. Only very few of the estimates apply exactly to the year 1990, so for each country we pick the estimate prior and closest to 1990. In total, there are approximately 90 countries with an estimate of the Mincerian return prior to 1990. Country-specific Mincerian returns and their date are shown in Appendix Table 4. For schooling attainment, we use the latest installment of the Barro and Lee data set (Barro and Lee, 2010), which breaks the labor force down into 7 attainment groups, no education, some primary school, primary school completed, some secondary school, secondary school completed, some college, and college completed. These are observed in 1990 for all countries. For the reference country, we again take the US. ${ }^{13}$

Figure 2 shows the results of implementing (11) on our sample of 90 countries. For each country, we plot the upper bound on the right side of (11) against real output per worker in PPP in 1995 (from the Penn World Tables). Not surprisingly, poorer countries experience larger upper-bound increases in output when bringing their educational attainment in line with US levels. The detailed country-by-country numbers are reported in Appendix Table 4.

Table 3 shows summary statistics from implementing (11) on our sample of 90 countries. In general, compared to their starting point, several countries have seemingly large upper-bound increases in output

\footnotetext{
${ }^{13}$ To implement (11) we also need the average years of schooling of each of the attainment groups. This is also available in the Barro and Lee data set.
} 
associated with attaining US schooling levels (and the physical capital that goes with them). The largest upper bound is 3.66, meaning that output almost quadruples. At the 90th percentile of output gain, output roughly doubles, and at the 75 th percentile there is still a sizable increase by three quarters. The median increase is roughly $45 \%$. The average country has an upper-bound increase of $60 \%$.

Figure 3 plots the estimated upper bounds obtained using (11) as a percentage of the initial output gap with the US. ${ }^{14}$ Clearly the upperbound output gains for the poorest countries in the sample are small as a fraction of the gap with the US. For the poorest country the upperbound output gain is less than $1 \%$ of the gap with the US. For the country with the 10th percentile level of output per worker, the upperbound gain covers about $5 \%$ of the output gap. At the 25 th percentile of the output per worker distribution, the upper-bound gain covers about $7 \%$ of the output gap, and at the median it is around $20 \%$. The average upper-bound closing of the gap is $74 \%$, but this is driven by some very large outliers.

\section{Development Accounting and Endogenous Tech- nology}

A possible concern with the approach that characterizes the development accounting literature is that the production function is assumed to be invariant to changes in factor inputs. This may lead development accounting to misjudge the output gap that can be accounted for by input differences. The literature points to two main ways in which inputs may affect the production function. First, there may be a positive external effect of human capital on the overall efficiency of the economy (e.g. Nelson and Phelps, 1966; Romer, 1986; Lucas, 1988). For example, a larger number of schooled workers may make it more likely that the adaptation of an advanced technology to a particular country is profitable, which would lead countries with more schooling to have higher levels of TFP. Second, firms' technology choices may depend on the relative prices of different factors, which in turn depend on relative supplies. Such appropriate-technology considerations may lead the factor bias of the production function to change as the relative supply of workers with different quantity of schooling changes (e.g. Basu and Weil, 1998; Acemoglu, 1998, 2002; Caselli and Coleman, 2006).

We can formalize these concerns as follows. Denote the mapping

\footnotetext{
${ }^{14}$ For the purpose of this figure the sample has been trimmed at an income level of $\$ 60,000$ because the four countries above this level had very large values that visually dominated the picture.
} 
from a vector of input quantities $X$ to output $Y$ by

$$
Y=F(X, \theta(X))=H(X),
$$

where $\theta$ is a vector of parameters that depend on $X$ if there are externalities or if technology choice is affected by factor inputs. For example, in models with externalities that work through total factor productivity, the function $F$ may take the form $A(X) G(X)$, where $A(X)$ would capture that total factor productivity changes when factor quantities change. In models of appropriate technology $F$ may be written as $G(A(X) \otimes X)$, where $A(X)$ is a vector of input-specific efficiencies, which in turn may depend on the relative supplies of different inputs. ${ }^{15}$

Development accounting is often understood as asking about the effect of an increase in input quantities $X$ on output $Y$ holding $\theta$ constant at the initial level of $X$. That is, development accounting is about quantifying

$$
Y^{\prime}-Y=F\left(X^{\prime}, \theta(X)\right)-F(X, \theta(X)) .
$$

This is a well-defined exercise, but strong believers in externalities or appropriate technology may feel that it is of limited practical value if $\theta$ changes significantly with $X$. Such critics would find a calculation of $F\left(X^{\prime}, \theta\left(X^{\prime}\right)\right)-F(X, \theta(X))=H\left(X^{\prime}\right)-H(X)$ more informative.

Our upper-bound formula is derived for any aggregate production function featuring constant returns to scale and weak concavity. Hence, our upper-bound calculation is robust to endogenous technology if the function $H(X)$ satisfies these restrictions. Perhaps surprisingly, this is sometimes the case. Consider, in particular, the appropriate-technology framework developed and estimated, with considerable empirical success, by Caselli and Coleman (2006). The production function is

$$
\left[\left(A_{u} L_{u}\right)^{\sigma}+\left(A_{s} L_{s}\right)^{\sigma}\right]^{\frac{1}{\sigma}}
$$

where $L_{u}$ is unskilled labor, $L_{s}$ is skilled labor, $A_{u}$ and $A_{s}$ are factoraugmenting technology terms, and $1 /(1-\sigma)$ is the elasticity of substitution between skilled and unskilled labor. Perfectly competitive firms in each country choose both inputs $L_{u}$ and $L_{s}$ and factor-augmenting technology terms $A_{u}$ and $A_{s}$, subject to the production function in (17) and a technology menu given by

$$
A_{s}^{\omega}+\gamma A_{u}^{\omega} \leq B,
$$

where $\gamma$ and $B$ are exogenous parameters. Under the parameter restriction $\omega>1 /(1-\sigma)$, which is consistent with Caselli and Coleman's

\footnotetext{
${ }^{15}$ The symbol $\otimes$ denotes the Kronecker product.
} 
estimates, it can be shown that the optimal technology choice of firms is given by

$$
A_{u}=\frac{B}{\left(1+\gamma^{\frac{\sigma}{\sigma-\omega}} L_{s}^{\frac{\omega \sigma}{\omega-\sigma}} L_{u}^{\frac{\omega \sigma}{\sigma-\omega}}\right)^{\frac{1}{\omega}}} \text { and } A_{s}=\frac{B / \gamma}{\left(1+\gamma^{\frac{\sigma}{\omega-\sigma}} L_{u}^{\frac{\omega \sigma}{\omega-\sigma}} L_{s}^{\frac{\omega \sigma}{\sigma-\omega}}\right)^{\frac{1}{\omega}}}
$$

Plugging (19) in the production function in (17) we obtain the equivalent of $H(X)$, or the full mapping from inputs to outputs when endogenous technology is accounted for. It can be shown that this function features constant returns to scale and is concave, which implies that, at least in this case, our proposed approach still delivers an upper bound on the increase in income associated with a certain increase in schooling capital.

On the other hand, our upper-bound approach will generally not work if there are schooling externalities that induce aggregate increasing returns. This is clearly a limitation of our approach (and development accounting in general). On the other hand, contrary to the case of appropriate technology, the evidence for quantitatively large aggregate schooling externalities is not very strong, suggesting that such externalities are unlikely in practice to significantly affect our quantitative findings. ${ }^{16}$ Instrumental-variables approaches suggest that there are no significant aggregate externalities to high-school attainment (e.g. Acemoglu and Angrist, 2001; Ciccone and Peri, 2006; Iranzo and Peri, 2009). And while there do appear to be some aggregate externalities to college attainment (Moretti, 2004; Iranzo and Peri, 2009), they seem to be too small to overturn our main conclusion. According to Iranzo and Peri, an additional year of schooling due to college attainment raises total factor productivity by around $5 \%$. For the typical poor country, taking college attainment to the level of the US in 1990 would add less than 4 years to average years of schooling . Hence, schooling externalities would add around $30 \%$ to our upper bound once the induced increase in the physical capital intensity is accounted for. ${ }^{17}$ While this is not negligible, it remains too small to significantly increase the fraction of the output gap being closed relative to our calculations.

\section{Conclusion}

How much of the output gap with rich countries can developing countries close by increasing their quantity of schooling? Our approach has been to look at the best-case scenario: an upper bound for the increase in

\footnotetext{
${ }^{16}$ For a review of evidence on schooling externalities at the microeconomic level, see Rosenzweig (2012).

${ }^{17}$ This calculation assumes that the elasticity of output with respect to physical capital is 0.33 , see Gollin (2002).
} 
output that can be achieved by more schooling. The main advantage of our approach is that the upper bound is valid for an arbitrary number of schooling levels with arbitrary patterns of substitution/complementarity. Another advantage is that the upper bound is robust to certain forms of endogenous technology response to changes in schooling. Application of our upper-bound calculations to two different data sets yields output gains from reaching a distribution of schooling attainment similar to the US that are sizeable as a proportion of initial output. However, these gains are much smaller when measured as a proportion of the existing output gap with the US. This result is in line with the conclusions from the development accounting literature, which is not surprising as many development accounting studies assume that workers with different schooling attainment are perfect substitutes and therefore end up employing a formula that is very similar to our upper bound. 


\section{Appendix: Non-Separability between Physical Cap- ital and Schooling}

Since Griliches (1969) and Fallon and Layard (1975), it has been argued that physical capital displays stronger complementaries with highskilled than low-skilled workers (see also Krusell et al., 2000; Caselli and Coleman 2002, 2006; and Duffy et al. 2004). In this case, schooling may generate additional productivity gains through the complementarity with physical capital. We therefore extend our analysis to allow for capital-skill complementarities and derive the corresponding upper bound for the increase in output per worker that can be generated by additional schooling.

To allow for capital-skill complementarities, suppose that the production function is

$$
Y=F\left(Q\left[U\left(L_{0}, . ., L_{\tau-1}\right), H\left(L_{\tau}, . ., L_{m}\right)\right], G\left[K, H\left(L_{\tau}, . ., L_{m}\right)\right]\right)
$$

where $F, Q, U$, and $H$ are characterized by constant returns to scale and weak concavity, and $G$ by constant returns to scale and $G_{12}<0$ to ensure capital-skill complementarities. This production function encompasses the functional forms by Fallon and Layard (1975), Krusell et al. (2000), Caselli and Coleman (2002, 2006), and Goldin and Katz (1998) for example (who assume that $F, G$ are constant-elasticity-of-substitution functions, that $Q(U, H)=U$, and that $U, H$ are linear functions). ${ }^{18}$ The main advantage of our approach is that we do not need to specify functional forms and substitution parameters, which is notoriously difficult (e.g. Duffy et al., 2004).

To develop an upper bound for the increase in output per worker that can be generated by increased schooling in the presence of capital-skill complementarities, we need an additional assumption compared to the scenario with weak separability between physical capital and schooling. The assumption is that the change in the schooling distribution from $\mathbf{s}^{1}$ to $\mathrm{s}^{2}$ does not strictly lower the skill ratio $H / U$, that is,

$$
\frac{H\left(\mathbf{s}_{2}^{2}\right)}{U\left(\mathbf{s}_{1}^{2}\right)} \geq \frac{H\left(\mathbf{s}_{2}^{1}\right)}{U\left(\mathbf{s}_{1}^{1}\right)}
$$

where $\mathbf{s}_{1}=\left[s_{0}, \ldots, s_{\tau-1}\right]$ collects the shares of workers with schooling levels strictly below $\tau$ and $\mathbf{s}_{2}=\left[s_{\tau}, \ldots, s_{m}\right]$ collects the shares of workers with schooling levels equal or higher than $\tau$ (we continue to use the superscript 1 to denote the original schooling shares and the superscript

\footnotetext{
${ }^{18}$ Duffy et al. (2004) argue that a special case of the formulation in (20) fits the empirical evidence better than alternative formulations for capital-skill complementarities used in the literature.
} 
2 for the counterfactual schooling distribution). For example, this assumption will be satisfied if the counterfactual schooling distribution has lower shares of workers with schooling attainment $i<\tau$ and higher shares of workers with schooling attainment $i \geq \tau$. If $U, H$ are linear function as in Fallon and Layard (1975), Krusell et al. (2000), Caselli and Coleman $(2002,2006)$, and Goldin and Katz (1998), the assumption in (21) is testable as it is equivalent to

$$
\frac{\sum_{i=0}^{\tau-1} \frac{w_{i}^{1}}{w_{0}^{1}}\left(s_{i}^{2}-s_{i}^{1}\right)}{\sum_{i=0}^{\tau-1} \frac{w_{i}^{1}}{w_{0}^{1}} s_{i}^{1}} \leq \frac{\sum_{i=\tau}^{m} \frac{w_{i}^{1}}{w_{\tau}^{1}}\left(s_{i}^{2}-s_{i}^{1}\right)}{\sum_{i=\tau}^{m} \frac{w_{i}^{1}}{w_{\tau}^{1}} s_{i}^{1}},
$$

where we used that competitive factor markets and (20) imply $w_{i}^{1} / w_{0}^{1}=$ $F_{1} Q_{1} U_{i} / F_{1} Q_{1} U_{0}=U_{i} / U_{0}$ for $i<\tau$ and $w_{i}^{1} / w_{\tau}^{1}=\left(F_{1} Q_{2}+F_{2} G_{2}\right) H_{i}$ $/\left(F_{1} Q_{2}+F_{2} G_{2}\right) H_{\tau}=H_{i} / H_{\tau}$ for $i \geq \tau$.

It can now be shown that the optimal physical capital adjustment implies

$$
\frac{k^{2}-k^{1}}{k^{1}} \leq \frac{H\left(\mathbf{s}_{2}^{2}\right)-H\left(\mathbf{s}_{2}^{1}\right)}{H\left(\mathbf{s}_{2}^{1}\right)}
$$

To see this, note that the marginal product of capital implied by (20) is

$$
M P K=F_{2}\left(1, \frac{G\left[\frac{k}{H\left(\mathbf{s}_{2}\right)}, 1\right]}{Q\left[\frac{U\left(\mathbf{s}_{1}\right)}{H\left(\mathbf{s}_{2}\right)}, 1\right]}\right) G_{1}\left[\frac{k}{H\left(\mathbf{s}_{2}\right)}, 1\right] .
$$

Hence, holding $k / H$ constant, an increase in $H / U$ either lowers the marginal product of capital or leaves it unchanged. As a result, $k / H$ must fall or remain constant to leave the marginal product of physical capital unchanged, which implies (23).

Using steps that are similar to those in the derivation of (9) we obtain

$$
\frac{U\left(\mathbf{s}_{1}^{2}\right)-U\left(\mathbf{s}_{1}^{1}\right)}{U\left(\mathbf{s}_{1}^{1}\right)} \leq \frac{\sum_{i=0}^{\tau-1} \frac{w_{i}^{1}}{w_{0}^{1}}\left(s_{i}^{2}-s_{i}^{1}\right)}{\sum_{i=0}^{\tau-1} \frac{w_{i}^{1}}{w_{0}^{1}} s_{i}^{1}},
$$


where we used $w_{i}^{1} / w_{0}^{1}=\left(F_{1} Q_{1} U_{i}\right) /\left(F_{1} Q_{1} U_{0}\right)=H_{i} / H_{\tau}$ for $i<\tau$, and

$$
\frac{k^{2}-k^{1}}{k^{1}} \leq \frac{H\left(\mathbf{s}_{2}^{2}\right)-H\left(\mathbf{s}_{2}^{1}\right)}{H\left(\mathbf{s}_{2}^{1}\right)} \leq \frac{\sum_{i=\tau}^{m} \frac{w_{i}^{1}}{w_{\tau}^{1}}\left(s_{i}^{2}-s_{i}^{1}\right)}{\sum_{i=\tau}^{m} \frac{w_{i}^{1}}{w_{\tau}^{1}} s_{i}^{1}},
$$

where we used $w_{i}^{1} / w_{\tau}^{1}=\left(F_{1} Q_{2} H_{i}+F_{2} G_{2} H_{i}\right) /\left(F_{1} Q_{2} H_{\tau}+F_{2} G_{2} H_{\tau}\right)=$ $H_{i} / H_{\tau}$ for $i \geq \tau$ and (23). These last two inequalities combined with (20) imply

$$
\frac{y^{2}-y^{1}}{y^{1}} \leq \beta^{1}\left(\frac{\sum_{i=0}^{\tau-1} \frac{w_{i}^{1}}{w_{0}^{1}}\left(s_{i}^{2}-s_{i}^{1}\right)}{\sum_{i=0}^{\tau-1} \frac{w_{i}^{1}}{w_{0}^{1}} s_{i}^{1}}\right)+\left(1-\beta^{1}\right)\left(\frac{\sum_{i=\tau}^{m} \frac{w_{i}^{1}}{w_{\tau}^{1}}\left(s_{i}^{2}-s_{i}^{1}\right)}{\sum_{i=\tau}^{m} \frac{w_{i}^{1}}{w_{\tau}^{1}} s_{i}^{1}}\right),
$$

where $\beta^{1}$ is the share of workers with schooling levels $i<\tau$ in aggregate income. Hence, with capital-skill complementarities, the increase in output per worker that can be generated by additional schooling is below a bound that depends on the income share of workers with schooling levels $i<\tau$ and the wage premia of different schooling groups relative to two schooling baselines (attainment 0 and attainment $\tau$ ).

To get some intuition on the difference between the upper bound in (9) and in (27), note that the upper bound in (27) would be identical to the upper bound in (9) if, instead of $\beta^{1}$, we were to use the share of workers with schooling levels $i<\tau$ in aggregate wage income. Hence, as the share of workers with low schooling in aggregate wage income is greater than their share in aggregate income, (27) puts less weight on workers with low schooling and more weight on workers with more schooling than (9) (except if there is no physical capital). This is because of the stronger complementarity of better-schooled workers with physical capital. ${ }^{19}$

\footnotetext{
${ }^{19}$ The main difficulty in estimating $\beta^{1}$ is defining threshold schooling $\tau$. If $\tau$ was college attainment, the upper bound could be quite large because developing countries have very low college shares and the increase in college workers would be weighted by the physical capital income share plus the college-worker income share (rather than the much smaller college-worker income share only). If $\tau$ is secondary school, the difference with our calculations would be small.
} 


\section{References}

Acemoglu, Daron, 1998. "Why Do New Technologies Complement Skills? Directed Technical Change and Wage Inequality." Quarterly Journal of Economics, 113, pp. 1055-1089.

Acemoglu Daron and Joshua Angrist, 2001. "How Large are HumanCapital Externalities? Evidence from Compulsory-Schooling Laws." In NBER Macroeconomic Annual, MIT Press.

Acemoglu, Daron, 2002. "Directed Technical Change." Review of Economic Studies, 69, pp. 781-810.

Angrist, Joshua, 1995. "The Economic Returns to Schooling in the West Bank and Gaza Strip." American Economic Review, 85, pp. 1065-1087.

Autor, David, and Lawrence Katz, 1999. "Changes in the Wage Structure and Earnings Inequality." In Orley Ashenfelter and David Card, Handbook of Labor Economics, Elsevier.

Autor, David, Lawrence Katz and Melissa Kearney, 2006. "The Polarization of the U.S. Labor Market." American Economic Review Papers and Proceedings, 96, pp. 189-194.

Barro, Robert, 1991. "Economic Growth in a Cross-Section of Countries." Quarterly Journal of Economics, 106, pp. 407-43.

Barro, Robert and Lee, Jong-Wha, 2010. "A New Data Set of Educational Attainment in the World, 1950-2010." National Bureau of Economic Research Working Paper \#15902, Cambridge, MA. Data downloadable at: http://www.barrolee.com/

Basu, Susanto, and David Weil, 1998. "Appropriate Technology and Growth." The Quarterly Journal of Economics, 113, pp. 1025-1054.

Benhabib, Jess and Mark Spiegel, 1994. "The Role of Human Capital in Economic Development: Evidence from Aggregate Cross-Country Data." Journal of Monetary Economics, 34, pp. 143-173.

Bils, Mark and Pete Klenow, 2000. "Does Schooling Cause Growth?" American Economic Review, 90, pp. 1160-1183.

Card, David, 1999. "The Causal Effect of Education on Earnings." In Orley Ashenfelter and David Card, Handbook of Labor Economics, Elsevier. 
Caselli, Francesco, Gerardo Esquivel and Fernando Lefort, 1996. "Reopening the Convergence Debate: A New Look at Cross-Country Growth Empirics." Journal of Economic Growth, 3, pp. 363-389.

Caselli, Francesco and Coleman, John Wilbur II, 2002. "The U.S. Technology Frontier." American Economic Review, Papers and Proceedings, 92, pp. 148-152.

Caselli, Francesco and Coleman, John Wilbur II, 2006. "The World Technology Frontier." American Economic Review, 96, pp. 499-522.

Caselli, Francesco, and James Feyrer, 2007. "The Marginal Product of Capital." Quarterly Journal of Economics, 122, pp. 535-568.

Caselli, Francesco, 2010. Differences in Technology Across Time and Space. 2010 CREI Lectures, Slide Presentation. http://personal.lse.ac.uk/casellif/

Ciccone, Antonio, and Giovanni Peri, 2005. "Long-Run Substitutability Between More and Less Educated Workers: Evidence from US States 1950-1990." Review of Economics and Statistics, 87, pp. 652663.

Duffy, John, Chris Papageorgiou, and Fidel Perez-Sebastian, 2004. "Capital-Skill Complementarity? Evidence from a Panel of Countries." Review of Economics and Statistics, 86, pp. 327-344.

Duflo, Esther, 2001. "Schooling and Labor Market Consequences of School Construction in Indonesia: Evidence from an Unusual Policy Experiment." American Economic Review, 91, pp. 795-813.

Erosa, Andres, Tatyana Koreshkova and Diego Restuccia, 2010. "How Important is Human Capital? A Quantitative Theory of World Income Distribution." Review of Economic Studies, 77, pp. 14211449.

Fallon, Peter, and Richard Layard, 1971. "Capital-Skill Complementarity, Income Distribution, and Output Accounting." Journal of Political Economy, 83, pp. 279-302.

Foster, Andrew and Mark Rosenzweig, 1995. "Technical Change and Human Capital Returns and Investments: Evidence from the Green Revolution." American Economic Review, 86, pp. 931-953.

Gennaioli, Nicola, Rafael La Porta, Florencio Lopez-de-Silanes, and Andrei Shleifer, 2012. "Human Capital and Regional Development." Forthcoming, Quarterly Journal of Economics. 
Goldin, Caudia, and Lawrence Katz, 1998. "The Origins of TechnologySkill Complementarity." Quarterly Journal of Economics, 113, pp. 693-732.

Goldin, Claudia and Lawrence Katz, 2008. The Race Between Education and Technology. Harvard University Press.

Gollin, Douglas, 2002. "Getting Income Shares Right." Journal of Political Economy, 110, pp. 458-474.

Goos, Maarten, and Alan Manning, 2007. "Lousy and Lovely Jobs: The Rising Polarization of Work in Britain." Review of Economics and Statistics, 89, pp. 118-133.

Griliches, Zvi, 1969. "Capital-Skill Complementarity." Review of Economics and Statistics, 51, pp. 465-468.

Hall, Robert and Charles Jones, 1999. "Why Do Some Countries Produce So Much More Output Per Worker Than Others?" Quarterly Journal of Economics, 114, pp. 83-116.

Hanushek, Eric, and Ludger Woessmann. 2008. "The Role of Cognitive Skills in Economic Development." Journal of Economic Literature, 46, pp. 607-668.

Hanushek, Eric, and Ludger Woessmann, 2011. "The Economics of International Differences in Educational Achievement." In Eric Hanushek, Stephen Machin, and Ludger Woessmann, Handbook of the Economics of Education, North Holland.

Hendricks, Lutz, 2002. "How Important is Human Capital for Development? Evidence from Immigrant Earnings." American Economic Review, 92, pp. 198-219.

Iranzo, Susana and Giovanni Peri, 2009. "Schooling Externalities, Technology, and Productivity: Theory and Evidence from US States." Review of Economics and Statistics, 91, pp. 420-431.

Jensen, Robert, 2010. "The (Perceived) Returns to Education and the Demand for Schooling." Quarterly Journal of Economics, 125, pp. 515-548.

Jones, Ben, 2011. "The Human Capital Stock: A Generalized Approach." Northwestern University. 
Katz, Lawrence, and Kevin Murphy, 1992. "Changes in Relative Wages 1963-1987: Supply and Demand Factors." Quarterly Journal of Economics, 107, pp. 35-78.

Klenow, Peter, and Andres Rodriguez-Claire, 1997. "The Neoclassical Revival in Growth Economics: Has It Gone Too Far?". In NBER Macroeconomic Annual, MIT Press.

Krueger, Alan and Mikael Lindhal, 2001. "Education for Growth: Why and For Whom?"” Journal of Economic Literature, XXXIX, pp. $1101-1136$.

Krusell, Per, Lee Ohanian, Victor Rios-Rull, and Gianluca Violante, 2002. "Capital-Skill Complementarity and Inequality: A Macroeconomic Analysis." Econometrica 68, pp. 1029-1053.

Lagakos, David, Ben Moll, Tommaso Porzio and Nancy Qian, 2012. "Experience Matters: Human Capital and Development Accounting," Yale University.

Lucas, Robert, 1988. "On the Mechanics of Economic Development." Journal of Monetary Economics, 22, pp. 3-42.

Manuelli, Rodolfo, and Ananth Sheshadri, 2010. "Human Capital and the Wealth of Nations." University of Wisconsin.

Mankiw, Gregory, David Romer, and David Weil, 1992. "A Contribution to the Empirics of Growth." Quarterly Journal of Economics, 107, pp. 407-437.

McFadden, Daniel, Peter Diamond, and Miguel Rodriguez, 1978. "Measurement of the Elasticity of Factor Substitution and the Bias of Technical Change." In Melvyn Fuss and Daniel McFadden, Production Economics: A Dual Approach to Theory and Applications, Elsevier.

Minnesota Population Center. Integrated Public Use Microdata Series, International (IPUMS), 2011. Version 6.1 [Machine-Readable Database.]. Minneapolis: University of Minnesota. Data downloadable at: http://www.international.ipums.org

Moretti, Enrico, 2004. "Workers' Education, Spillovers, and Productivity: Evidence from Plant-Level Production Functions." American Economic Review, 94, pp. 656-690. 
Nelson, Richard, and Edmund Phelps, 1966. "Investment in Humans, Technological Diffusion, and Economic Growth." American Economic Review: Papers and Proceedings, 51, pp. 69-75.

Munshi, Kaivan and Mark Rosenzweig, 2006. "Traditional Institutions Meet the Modern World: Caste, Gender, and Schooling Choice in a Globalizing Economy." American Economic Review, 96, pp. 12251252 .

Rosenzweig, Mark, 2012. "Microeconometric Evidence on the Role of Schooling in the Growth Process." Slide Presentation. http://www2.iies.su.se/Nobel2012/Presentations/Rosenzweig.pdf

Schultz, Paul, 2004. "School Subsidies for the Poor: Evaluating the Mexican Progresa Poverty Program." Journal of Development Economics, 74, pp.199-250.

Romer, Paul, 1986. "Increasing Returns and Long-Run Growth." Journal of Political Economy, 94, pp.1002-1037.

Weil, David, 2007. "Accounting for the Effect of Health on Economic Growth." Quarterly Journal of Economics, 122, pp.1265-1306. 


\section{Figure 1: Change in Income from Change in Schooling}

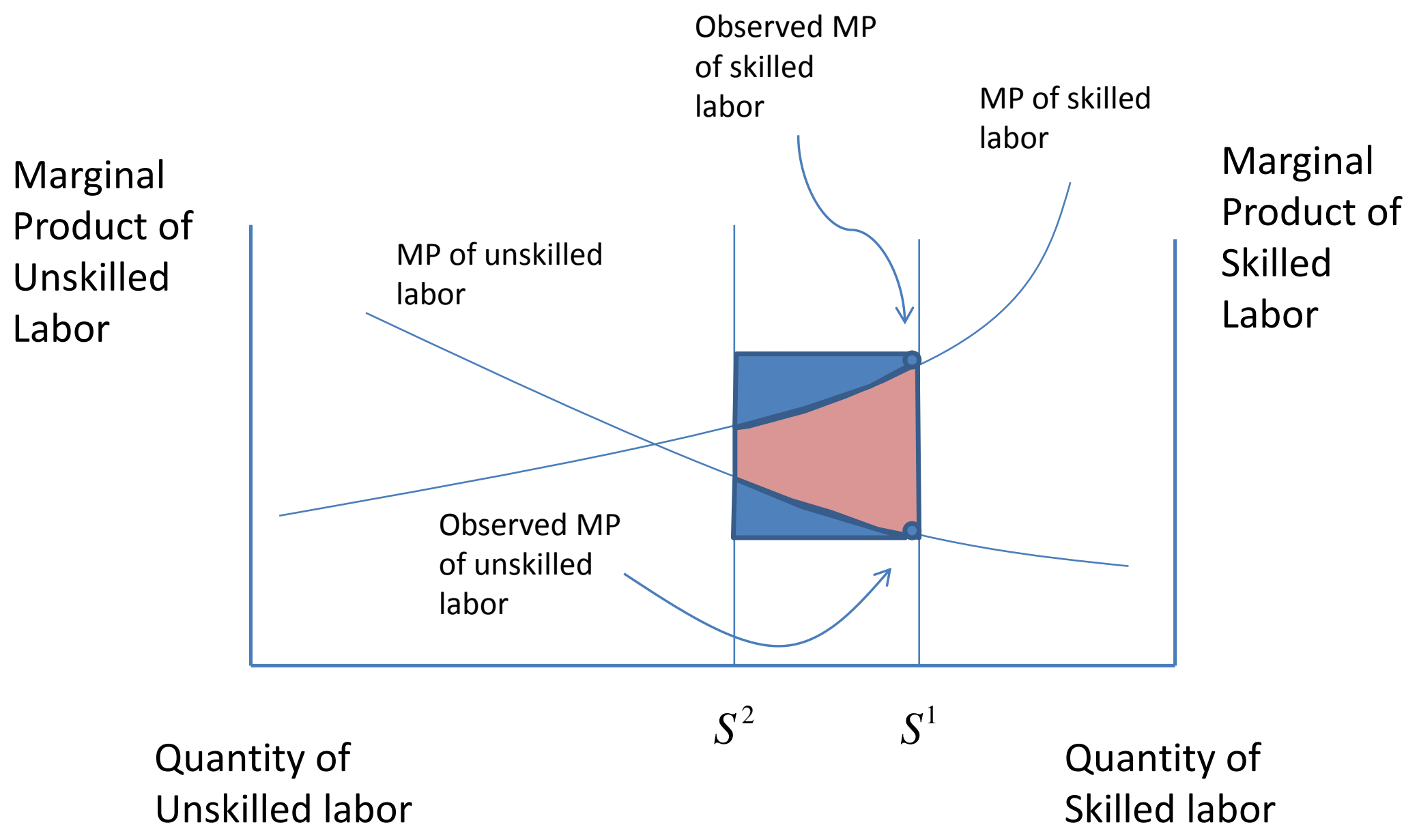


Figure 2: Upper-bound income increase from moving to US attainment

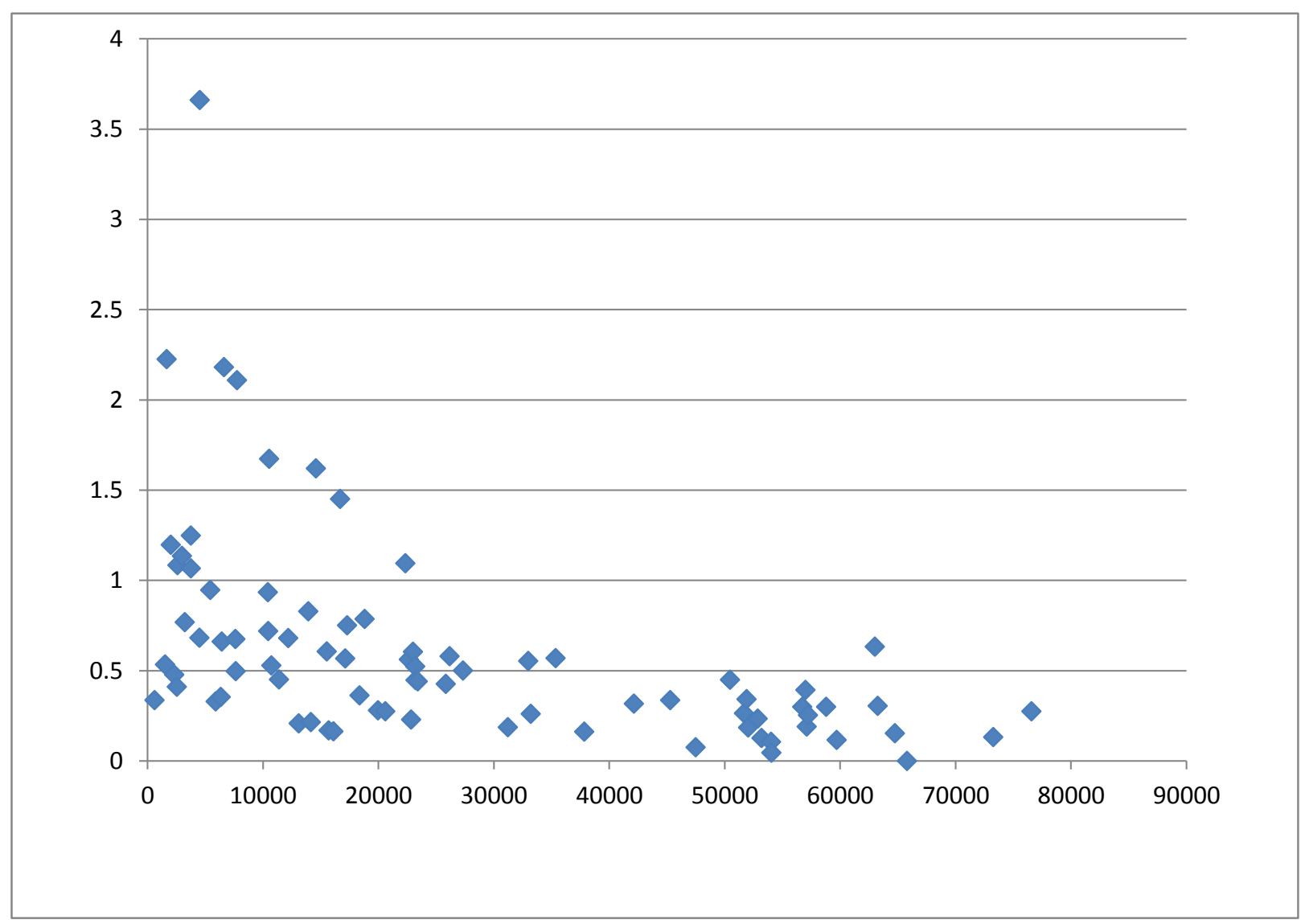


Figure 3: Upper-bound income increase as percent of income gap with US

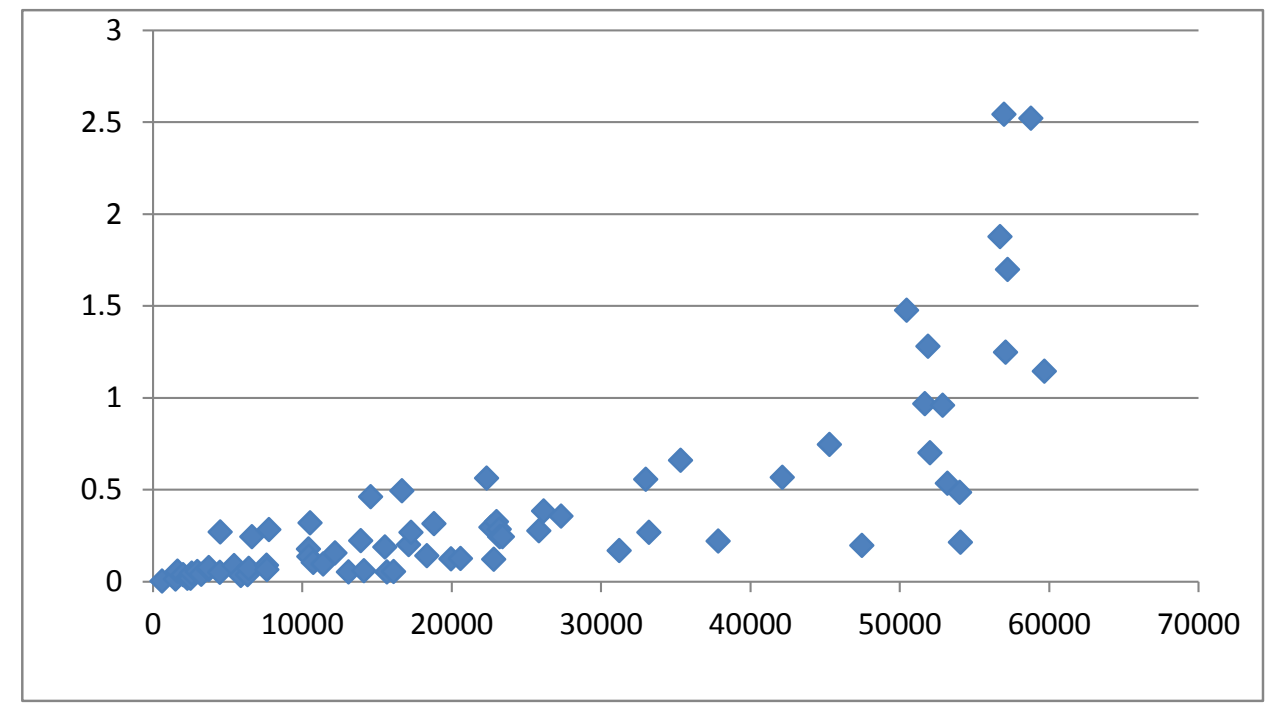


Table 1: Upper-bound income increase from moving to US attainment

\begin{tabular}{|c|c|c|c|c|c|c|c|}
\hline & 1960 & 1970 & 1980 & 1990 & 1995 & 2000 & 2005 \\
\hline \multirow{2}{*}{ Brazil } & & 1.576 & 1.201 & 1.020 & & 0.901 & \\
\hline & & 0.441 & 0.567 & 0.304 & & 0.224 & \\
\hline \multirow{2}{*}{ Colombia } & & 0.901 & & & & & \\
\hline & & 0.159 & & & & & \\
\hline \multirow{2}{*}{ Jamaica } & & & 0.620 & 0.242 & & 0.469 & \\
\hline & & & 0.209 & 0.076 & & 0.135 & \\
\hline \multirow{2}{*}{ India } & & & 0.908 & 0.945 & 0.769 & 0.792 & 0.769 \\
\hline & & & 0.053 & 0.056 & 0.047 & 0.054 & 0.06 \\
\hline \multirow{2}{*}{ Mexico } & 1.238 & 0.916 & & 0.439 & 0.543 & 0.543 & \\
\hline & 0.524 & 0.411 & & 0.169 & 0.187 & 0.201 & \\
\hline \multirow{2}{*}{ Panama } & & 0.434 & 0.408 & 0.331 & & 0.255 & \\
\hline & & 0.088 & 0.109 & 0.072 & & 0.055 & \\
\hline \multirow{2}{*}{ Puerto Rico } & & 0.202 & 0.108 & 0.045 & & -0.003 & -0.012 \\
\hline & & 0.209 & 0.111 & 0.061 & & -0.006 & -0.019 \\
\hline \multirow{2}{*}{ South Africa } & & & & & 0.745 & 0.708 & 0.609 \\
\hline & & & & & 0.140 & 0.129 & 0.130 \\
\hline \multirow{2}{*}{ Venezuela } & & 0.757 & 0.604 & 0.403 & & 0.860 & \\
\hline & & 0.568 & 0.353 & 0.132 & & 0.235 & \\
\hline
\end{tabular}

Figures in bold type are percent income increases, based on equation (9)

[i.e. use attainment-specific returns to education]

Figures in normal type are percent income increases as share of income gap with US.

1970 figure refers to 1971 for Venezuela and 1973 for Colombia;

1980 figure refers to 1981 for Venezuela, 1982 for Jamaica, and 1983 for India;

1990 figure refers to 1987 for India and 1991 for Brazil and Jamaica;

1995 figure refers to 1993 for India and 1996 for South Africa;

2000 figure refers to 1999 for India and 2001 for Jamaica, South Africa, and Venezuela;

2005 figure refers to 2004 for India and 2007 for South Africa 
Table 2: Alternative measures of upper-bound income increase from moving to US attainment

\begin{tabular}{|c|c|c|c|c|c|c|c|}
\hline & 1960 & 1970 & 1980 & 1990 & 1995 & 2000 & 2005 \\
\hline \multirow{2}{*}{ Brazil } & & 0.828 & 0.749 & 0.743 & & 0.657 & \\
\hline & & 0.816 & 0.821 & 0.880 & & 0.773 & \\
\hline \multirow{2}{*}{ Colombia } & & 0.839 & & & & & \\
\hline & & 0.873 & & & & & \\
\hline \multirow{2}{*}{ Jamaica } & & & 1.052 & 1.269 & & 0.439 & \\
\hline & & & 1.092 & 1.255 & & 0.431 & \\
\hline \multirow{2}{*}{ India } & & & 0.915 & 0.954 & 0.907 & 0.866 & 0.842 \\
\hline & & & 1.037 & 1.100 & 1.042 & 1.017 & 1.000 \\
\hline \multirow{2}{*}{ Mexico } & 1.137 & 1.195 & & 0.983 & 1.109 & 0.886 & \\
\hline & 1.049 & 1.105 & & 1.055 & 1.311 & 1.024 & \\
\hline \multirow{2}{*}{ Panama } & & 0.934 & 0.984 & 0.978 & & 1.017 & \\
\hline & & 1.065 & 1.202 & 1.231 & & 1.278 & \\
\hline \multirow{2}{*}{ Puerto Rico } & & 0.996 & 1.023 & 0.992 & & -1.748 & 0.134 \\
\hline & & 1.237 & 1.285 & 1.369 & & -4.333 & -0.479 \\
\hline \multirow{2}{*}{ South Africa } & & & & & 0.711 & 0.612 & 0.694 \\
\hline & & & & & 0.861 & 0.739 & 0.855 \\
\hline \multirow{2}{*}{ Venezuela } & & 0.693 & 0.917 & 1.112 & & 0.283 & \\
\hline & & 0.612 & 0.958 & 1.172 & & 0.283 & \\
\hline
\end{tabular}

Figures in bold type assume constant returns to each additional year of schooling [based on equation (11)]; Figures in nornal type assume constant returns and assign to all workers the average years of schooling [based on equation (12)];

1970 figure refers to 1971 for Venezuela and 1973 for Colombia;

1980 figure refers to 1981 for Venezuela, 1982 for Jamaica, and 1983 for India;

1990 figure refers to 1987 for India and 1991 for Brazil and Jamaica;

1995 figure refers to 1993 for India and 1996 for South Africa;

2000 figure refers to 1999 for India and 2001 for Jamaica, South Africa, and Venezuela;

2005 figure refers to 2004 for India and 2007 for South Africa 
Table 3: Upper-bound income increase in a large cross section

assuming constant returns to each additional year of schooling

\begin{tabular}{|lccccc|}
\hline \multicolumn{7}{|c|}{ mean } & $\max$ & 90th percentile & 75th percentile & median \\
\hline \% Income increase based on (11) & 0.61 & 3.66 & 1.20 & 0.68 & 0.45 \\
\hline \% Income increase based on (12) & 0.80 & 7.59 & 1.48 & 0.82 & 0.54 \\
\hline
\end{tabular}


Appendix Table 1: Description of individual-level data

\begin{tabular}{|c|c|}
\hline Brazil & $\begin{array}{l}\text { Income concept used in the analysis: total income per hour worked for } 1980,1991 \text {, } \\
2000 ; \text { total income for } 1970 . \\
\text { Other income concepts available: earned income per hour worked for } 1980,1991 \text {, } \\
2000 \text { (yield nearly identical results as income concept used for } 1991 \text { and } 2000 \text { but } \\
\text { a significantly negative return to schooling in 1980). } \\
\text { Control variables used in the analysis: age, age squared, gender, marital status, } \\
\text { age*marital status, gender*marital status, dummies for region (state) of birth, } \\
\text { dummies for region (state) of residence, dummy for urban area, dummy for foreign } \\
\text { born, dummies for religion, dummies for race (except 1970). } \\
\text { Educational attainment levels: } 8\end{array}$ \\
\hline Colombia & $\begin{array}{l}\text { Income concept used in the analysis: total income for } 1973 . \\
\text { Other income concepts available: none. } \\
\text { Control variables used in the analysis: age, age squared, gender, marital status, } \\
\text { age*marital status, gender*marital status, dummies for region (state) of birth, } \\
\text { dummies for region (municipality) of residence, dummy for urban area, dummy for } \\
\text { foreign born. } \\
\text { Educational attainment levels: } 9\end{array}$ \\
\hline India & $\begin{array}{l}\text { Income concept used in the analysis: wage income for 1983, 1987, 1993, 1999, } \\
2004 . \\
\text { Other income concepts available: none. } \\
\text { Control variables used in the analysis: age, age squared, gender, marital status, } \\
\text { age*marital status, gender*marital status, dummies for region (state) of residence, } \\
\text { dummy for urban area, dummies for religion. } \\
\text { Educational attainment levels: } 8\end{array}$ \\
\hline Jamaica & $\begin{array}{l}\text { Income concept used in the analysis: wage income for 1982, 1991, } 2001 . \\
\text { Other income concepts available: none. } \\
\text { Control variables used in the analysis: age, age squared, gender, marital status, } \\
\text { age*marital status, gender*marital status, dummies for region (parish) of birth, } \\
\text { dummies for region (parish) of residence, dummy for foreign born, dummies for } \\
\text { religion, dummies for race. } \\
\text { Educational attainment levels: } 7\end{array}$ \\
\hline Mexico & $\begin{array}{l}\text { Income concept used in the analysis: earned income per hour worked for } 1990 \text {, } \\
\text { 1995, 2000; earned income for } 1960 ; \text { total income for } 1970 . \\
\text { Other income concepts available: total income per hour for } 1995,2000 . \\
\text { Control variables used in the analysis: age, age squared, gender, marital status, } \\
\text { age*marital status, gender marital status, dummies for region (state) of birth, } \\
\text { dummies for region (state) of residence, dummy for urban area, dummy for foreign } \\
\text { born, dummies for religion (except 1995). } \\
\text { Educational attainment levels: } 10\end{array}$ \\
\hline
\end{tabular}

Note: Point estimates of the Mincerian regressions and the number of observations available are summarized in Appendix Tables 2 and 3. For more details on the variables see https://international.ipums.org/international/. 
Appendix Table 1: Continued

\begin{tabular}{|c|c|}
\hline Panama & $\begin{array}{l}\text { Income concept used in the analysis: wage income per hour worked for } 1990, \\
2000 ; \text { wage income for 1970; total income per hour worked for } 1980 . \\
\text { Other income concepts available: earned income per hour worked for 1990, } 2000 \text {; } \\
\text { total income per hour worked for } 1990 \text { (yield nearly identical results as income } \\
\text { concept used). } \\
\text { Control variables used in the analysis: age, age squared, gender, marital status, } \\
\text { age*marital status, gender*marital status, dummies for region (state) of birth } \\
\text { (except 1990), dummies for region (district) of residence, dummy for urban area } \\
\text { (except 1990), dummy for foreign born (except 1980). } \\
\text { Educational attainment levels: } 8\end{array}$ \\
\hline & $\begin{array}{l}\text { Income concept used in the analysis: wage income per hour worked for } 1970, \\
\text { 1980, 1990, 2000, } 2005 . \\
\text { Other income concepts available: total income per hour worked for 1970, 1980, } \\
\text { 1990, 2000, 2005; earned income per hour worked for 1990, 2000, } 2005 \text { (yield } \\
\text { nearly identical results as income concept used. } \\
\text { Control variables used in the analysis: age, age squared, gender, marital status, } \\
\text { age }{ }^{\star} \text { marital status, gendermarital status, dummies for region (metropolitan area) } \\
\text { of residence, dummy for foreign born, dummies for race (only 2000, 2005). } \\
\text { Educational attainment levels: } 8\end{array}$ \\
\hline & $\begin{array}{l}\text { Income concept used in the analysis: total income per hour worked for } 1996,2007 \text {; } \\
\text { total income for } 2001 . \\
\text { Other income concepts available: none. } \\
\text { Control variables used in the analysis: age, age squared, gender, marital status, } \\
\text { age*marital status, gender*marital status, dummies for region (province) of birth } \\
\text { (except 1996), dummies for region (municipality) of residence, dummy for foreign } \\
\text { born, dummies for religion (except 2007), dummies for race. } \\
\text { Educational attainment levels: } 6\end{array}$ \\
\hline Venezuela & $\begin{array}{l}\text { Income concept used in the analysis: earned income per hour worked for } 1971 \text {, } \\
1981,2001 \text {; earned income for } 1990 . \\
\text { Other income concepts available: total income per hour worked } 2001 \text { (yields a } \\
\text { Mincerian return to schooling of } 13.7 \% \text { as compared to } 4.4 \% \text { using earned } \\
\text { income). } \\
\text { Control variables used in the analysis: age, age squared, gender, marital status, } \\
\text { age*marital status, gender*marital status, dummies for region (state) of birth, } \\
\text { dummies for region (province) of residence, dummy for foreign born. } \\
\text { Educational attainment levels: } 10\end{array}$ \\
\hline
\end{tabular}

Note: point estimates of the Mincerian regressions and the number of observations available are summarized in Appendix Tables 2 and 3. For more details on the variables see https://international.ipums.org/international/. 
Appendix Table 2: Estimated Mincerian returns and robust standard errors in parentheses

\begin{tabular}{|c|c|c|c|c|c|c|c|}
\hline & 1960 & 1970 & 1980 & 1990 & 1995 & 2000 & 2005 \\
\hline Brazil & & $0,124(0,00005)$ & $0,113(0,00004)$ & $0,115(0,00004)$ & & $0,109(0,00003)$ & \\
\hline Colombia & & $0,0889(0,0005)$ & & & & & \\
\hline India & & & $0,083(0,00002)$ & $0,0866(0,00002)$ & $0,074(0,00002)$ & $0,0776(0,00001)$ & $0,0788(0,00001)$ \\
\hline Jamaica & & & $0,125(0,002)$ & $0,0573(0,002)$ & & $0,0614(0,001)$ & \\
\hline Mexico & $0,123(0,0002)$ & $0,0993(0,0001)$ & & $0,0682(0,0001)$ & $0,114(0,0001)$ & $0,094(0,0001)$ & \\
\hline Panama & & $0,0879(0,002)$ & $0,0911(0,0003)$ & $0,0941(0,0003)$ & & $0,0916(0,0005)$ & \\
\hline Puerto Rico & & $0,099(0,0003)$ & $0,088(0,0005)$ & $0,0938(0,0005)$ & & $0,0985(0,0005)$ & $0,116(0,0004)$ \\
\hline South Africa & & & & & $0,117(0,0001)$ & $0,11(0,0002)$ & $0,143(0,0002)$ \\
\hline Venezuela & & $0,0625(0,0005)$ & $0,0875(0,0003)$ & $0,0732(0,0002)$ & & $0,0443(0,0005)$ & \\
\hline
\end{tabular}

1970 figure refers to 1971 for Venezuela and 1973 for Colombia;

1980 figure refers to 1981 for Venezuela, 1982 for Jamaica, and 1983 for India;

1990 figure refers to 1987 for India and 1991 for Brazil and Jamaica;

1995 figure refers to 1993 for India and 1996 for South Africa;

2000 figure refers to 1999 for India and 2001 for Jamaica, South Africa, and Venezuela;

2005 figure refers to 2004 for India and 2007 for South Africa 
Appendix Table 3: Number of observations used in the individual-level Mincerian regressions

\begin{tabular}{|c|c|c|c|c|c|c|c|}
\hline & 1960 & 1970 & 1980 & 1990 & 1995 & 2000 & 2005 \\
\hline Brazil & & 14660440 & 24720720 & 33616046 & & 41010810 & \\
\hline Colombia & & 3127210 & & & & & \\
\hline India & & & 86928152 & 45901965 & 109703806 & 133891583 & 139597372 \\
\hline Jamaica & & & 255720 & 409100 & & 443629 & \\
\hline Mexico & 4470106 & 6183300 & & 14303270 & 18762057 & 21316086 & \\
\hline Panama & & 246250 & 367330 & 408540 & & 653460 & \\
\hline Puerto Rico & & 653200 & 775220 & 698772 & & 732668 & 1000738 \\
\hline South Africa & & & & & 6775030 & 8299308 & 9360012 \\
\hline Venezuela & & 1540174 & 2567310 & 3548928 & & 5038900 & \\
\hline
\end{tabular}

1970 figure refers to 1971 for Venezuela and 1973 for Colombia;

1980 figure refers to 1981 for Venezuela, 1982 for Jamaica, and 1983 for India;

1990 figure refers to 1987 for India and 1991 for Brazil and Jamaica;

1995 figure refers to 1993 for India and 1996 for South Africa;

2000 figure refers to 1999 for India and 2001 for Jamaica, South Africa, and Venezuela;

2005 figure refers to 2004 for India and 2007 for South Africa 
Appendix Table 4: Data and results for the large sample

Kuwait

Norway

Zimbabwe

Uganda

Vietnam

Ghana

Philippines

Nepal

Sri Lanka

China

Zambia

Cameroon

Peru

Estonia

Russian Federation

Kenya

Tanzania

Bulgaria

India

Bolivia

Indonesia

Sudan

Nicaragua

Honduras

Egypt

Dominican Republic

Slovak Republic

Poland

Croatia

Paraguay

Costa Rica

El Salvador

Czech Republic

Thailand

Ecuador

Sweden

Panama

Australia

Cyprus

Tunisia

Chile

Pakistan

\begin{tabular}{|c|c|c|c|c|c|c|}
\hline Output in & \% Gap & Minceri & return & \% Gain & \% Gain & $\%$ Gap \\
\hline 1995 & with US & Estimate & Year & using (11) & using (12) & closed \\
\hline 76562 & -0.14 & 4.5 & 1983 & 0.275 & 0.317 & -1.95 \\
\hline 73274 & -0.10 & 5.5 & 1995 & 0.132 & 0.141 & -1.29 \\
\hline 610 & 106.79 & 5.57 & 1994 & 0.337 & 0.370 & 0.00 \\
\hline 1525 & 42.13 & 5.1 & 1992 & 0.535 & 0.572 & 0.01 \\
\hline 2532 & 24.99 & 4.8 & 1992 & 0.411 & 0.425 & 0.02 \\
\hline 2313 & 27.44 & 7.1 & 1995 & 0.477 & 0.578 & 0.02 \\
\hline 5897 & 10.16 & 12.6 & 1998 & 0.330 & 0.411 & 0.03 \\
\hline 2008 & 31.76 & 9.7 & 1999 & 1.197 & 1.518 & 0.04 \\
\hline 6327 & 9.40 & 7 & 1981 & 0.355 & 0.408 & 0.04 \\
\hline 3234 & 19.34 & 12.2 & 1993 & 0.769 & 0.964 & 0.04 \\
\hline 2595 & 24.35 & 11.5 & 1994 & 1.084 & 1.342 & 0.04 \\
\hline 4490 & 13.65 & 6.45 & 1994 & 0.683 & 0.753 & 0.05 \\
\hline 13101 & 4.02 & 5.7 & 1990 & 0.207 & 0.239 & 0.05 \\
\hline 15679 & 3.20 & 5.4 & 1994 & 0.169 & 0.181 & 0.05 \\
\hline 16108 & 3.08 & 7.2 & 1996 & 0.165 & 0.172 & 0.05 \\
\hline 2979 & 21.08 & 11.39 & 1995 & 1.135 & 1.353 & 0.05 \\
\hline 1640 & 39.10 & 13.84 & 1991 & 2.225 & 2.676 & 0.06 \\
\hline 14140 & 3.65 & 5.25 & 1995 & 0.214 & 0.235 & 0.06 \\
\hline 3736 & 16.61 & 10.6 & 1995 & 1.067 & 1.421 & 0.06 \\
\hline 7624 & 7.63 & 10.7 & 1993 & 0.498 & 0.658 & 0.07 \\
\hline 6413 & 9.26 & 7 & 1995 & 0.661 & 0.758 & 0.07 \\
\hline 3747 & 16.56 & 9.3 & 1989 & 1.248 & 1.417 & 0.08 \\
\hline 5433 & 11.11 & 12.1 & 1996 & 0.947 & 1.303 & 0.09 \\
\hline 7599 & 7.66 & 9.3 & 1991 & 0.674 & 0.763 & 0.09 \\
\hline 11387 & 4.78 & 5.2 & 1997 & 0.452 & 0.511 & 0.09 \\
\hline 10739 & 5.13 & 9.4 & 1995 & 0.528 & 0.652 & 0.10 \\
\hline 22834 & 1.88 & 6.4 & 1995 & 0.229 & 0.265 & 0.12 \\
\hline 19960 & 2.30 & 7 & 1996 & 0.280 & 0.302 & 0.12 \\
\hline 20606 & 2.19 & 5 & 1996 & 0.274 & 0.299 & 0.13 \\
\hline 10450 & 5.30 & 11.5 & 1990 & 0.719 & 0.851 & 0.14 \\
\hline 18352 & 2.58 & 8.5 & 1991 & 0.362 & 0.411 & 0.14 \\
\hline 12182 & 4.40 & 7.6 & 1992 & 0.680 & 0.776 & 0.15 \\
\hline 31215 & 1.11 & 5.65 & 1995 & 0.186 & 0.210 & 0.17 \\
\hline 10414 & 5.32 & 11.5 & 1989 & 0.934 & 1.084 & 0.18 \\
\hline 15528 & 3.24 & 11.8 & 1995 & 0.606 & 0.820 & 0.19 \\
\hline 47480 & 0.39 & 3.56 & 1991 & 0.076 & 0.080 & 0.20 \\
\hline 17119 & 2.84 & 13.7 & 1990 & 0.568 & 0.770 & 0.20 \\
\hline 54055 & 0.22 & 8 & 1989 & 0.046 & 0.038 & 0.21 \\
\hline 37843 & 0.74 & 5.2 & 1994 & 0.162 & 0.178 & 0.22 \\
\hline 13927 & 3.72 & 8 & 1980 & 0.829 & 1.006 & 0.22 \\
\hline 23403 & 1.81 & 12.1 & 1989 & 0.442 & 0.546 & 0.24 \\
\hline 6624 & 8.93 & 15.4 & 1991 & 2.180 & 3.439 & 0.24 \\
\hline
\end{tabular}




\begin{tabular}{|c|c|c|c|c|c|c|c|}
\hline Argentina & 23222 & 1.83 & 10.3 & 1989 & 0.448 & 0.542 & 0.24 \\
\hline Korea, Rep. & 33210 & 0.98 & 13.5 & 1986 & 0.262 & 0.406 & 0.27 \\
\hline Botswana & 17280 & 2.81 & 12.6 & 1979 & 0.751 & 1.056 & 0.27 \\
\hline Cote d'Ivoire & 4512 & 13.58 & 20.1 & 1986 & 3.660 & 7.593 & 0.27 \\
\hline Mexico & 25835 & 1.55 & 7.6 & 1992 & 0.426 & 0.496 & 0.28 \\
\hline Morocco & 7759 & 7.48 & 15.8 & 1970 & 2.109 & 3.550 & 0.28 \\
\hline Malaysia & 23194 & 1.84 & 9.4 & 1979 & 0.524 & 0.657 & 0.29 \\
\hline South Africa & 22638 & 1.91 & 11 & 1993 & 0.562 & 0.668 & 0.29 \\
\hline Colombia & 18808 & 2.50 & 14.5 & 1989 & 0.787 & 1.044 & 0.32 \\
\hline Guatemala & 10530 & 5.25 & 14.9 & 1989 & 1.674 & 2.193 & 0.32 \\
\hline Turkey & 22996 & 1.86 & 9 & 1994 & 0.605 & 0.736 & 0.32 \\
\hline Hungary & 27326 & 1.41 & 8.9 & 1995 & 0.501 & 0.588 & 0.36 \\
\hline Venezuela, RB & 26164 & 1.51 & 9.4 & 1992 & 0.579 & 0.689 & 0.38 \\
\hline Jamaica & 14588 & 3.51 & 28.8 & 1989 & 1.621 & 2.268 & 0.46 \\
\hline Canada & 54026 & 0.22 & 8.9 & 1989 & 0.106 & 0.108 & 0.49 \\
\hline Brazil & 16676 & 2.95 & 14.7 & 1989 & 1.451 & 1.903 & 0.49 \\
\hline Israel & 53203 & 0.24 & 6.2 & 1995 & 0.126 & 0.149 & 0.53 \\
\hline Slovenia & 32991 & 0.99 & 9.8 & 1995 & 0.553 & 0.693 & 0.56 \\
\hline Iran, Islamic Rep. & 22339 & 1.95 & 11.6 & 1975 & 1.095 & 1.483 & 0.56 \\
\hline Greece & 42141 & 0.56 & 7.6 & 1993 & 0.318 & 0.368 & 0.57 \\
\hline Portugal & 35336 & 0.86 & 8.73 & 1994 & 0.569 & 0.658 & 0.66 \\
\hline Denmark & 52032 & 0.26 & 5.14 & 1995 & 0.185 & 0.197 & 0.70 \\
\hline Finland & 45289 & 0.45 & 8.2 & 1993 & 0.337 & 0.374 & 0.74 \\
\hline Ireland & 52868 & 0.24 & 9.81 & 1994 & 0.234 & 0.266 & 0.96 \\
\hline Japan & 51674 & 0.27 & 13.2 & 1988 & 0.264 & 0.333 & 0.97 \\
\hline Netherlands & 59684 & 0.10 & 6.4 & 1994 & 0.117 & 0.127 & 1.14 \\
\hline Hong Kong & 57093 & 0.15 & 6.1 & 1981 & 0.190 & 0.229 & 1.25 \\
\hline United Kingdom & 51901 & 0.27 & 9.3 & 1995 & 0.342 & 0.405 & 1.28 \\
\hline Spain & 50451 & 0.30 & 7.54 & 1994 & 0.449 & 0.541 & 1.48 \\
\hline Switzerland & 57209 & 0.15 & 7.5 & 1991 & 0.255 & 0.314 & 1.70 \\
\hline Austria & 56728 & 0.16 & 7.2 & 1993 & 0.300 & 0.331 & 1.88 \\
\hline France & 58784 & 0.12 & 7 & 1995 & 0.300 & 0.347 & 2.52 \\
\hline Germany & 56992 & 0.15 & 7.85 & 1995 & 0.392 & 0.480 & 2.54 \\
\hline Italy & 63260 & 0.04 & 6.19 & 1995 & 0.305 & 0.344 & 7.63 \\
\hline Belgium & 64751 & 0.02 & 6.3 & 1999 & 0.154 & 0.171 & 9.58 \\
\hline Singapore & 63009 & 0.04 & 13.1 & 1998 & 0.634 & 0.724 & 14.36 \\
\hline United States & 65788 & 0.00 & 10 & 1993 & 0.000 & 0.000 & n.a. \\
\hline Iraq & n.a. & n.a. & 6.4 & 1979 & 0.567 & 0.664 & n.a. \\
\hline Taiwan & n.a. & n.a. & 6 & 1972 & 0.330 & 0.293 & n.a. \\
\hline
\end{tabular}

Note: Output per worker from Penn World Tables. 